\title{
La escuela moderna y los \\ orígenes de la formación \\ cívica y moral en México, \\ 1790-1835
}

Jesús Márquez Carrillo jesusm146@hotmail.com
The modern school and the civic and moral formation origins in Mexico,

\section{Resumen}

Este trabajo subraya la importancia de una historia del currículum vinculada con la epistemología social del conocimiento. En primer lugar, tiene el propósito de mostrar brevemente la genealogía de la escuela y su estrecho vínculo con la modernidad; en segundo término, le interesa mostrar el entramado sociopolítico que propicia el surgimiento de la educación cívica y moral en México, y, finalmente, al describir y analizar los discursos de los libros escolares y las prácticas en la escuela, su objetivo es destacar el interés de las instituciones educativas por configurar un sujeto civilizado y un ciudadano moderno.

Palabras clave: política y escolarización, genealogía de la escuela moderna, historia del currículum, historia de la educación cívica y moral, discursos y prácticas escolares.

\section{Abstract}

This paper underlines the importance of curriculum history linked to the social epistemology of knowledge. Doing so, it wants to show briefly the genealogy of school and his link to modernity, and tries to underline the socio-political framework that enables the rise of civics and moral education in Mexico. Finally, this paper describes and analyzes the textbooks discourses as well as the internal practices in the schools. Its objective is to highlight the interest of educational institutes to form a civilized person and a modern citizen.

Keywords: politics and schooling, modern school genealogy, curriculum history, civics and moral education history, scholar discourses and practices. Benemérita Universidad Autónoma de Puebla, Centro de Estudios Universitarios, Facultad de Filosofía y Letras, México.

Av. Juan de Palafox y Mendoza núm. 227 Altos, Centro, 72000 Puebla, Puebla, México. 
En las últimas décadas del siglo pasado, diversas perspectivas teóricas y metodológicas estimularon el estudio histórico de la cultura escolar, y dentro de ella alcanzó especial importancia la historia del currículum, una de cuyas vertientes es la historia de las disciplinas escolares y sus libros, que hoy se cultiva en más de sesenta países. ${ }^{2}$ En México este asunto tuvo un crecimiento notorio a partir de los años noventa. ${ }^{3}$ En esa época, tanto el surgimiento de la "nueva historia política" como la crisis política del país favorecieron el impulso de la investigación histórica sobre las sociabilidades modernas, los orígenes y el desarrollo del sistema político mexicano, la idea de ciudadanía en el mundo hispánico o el problema de la formación cívica y moral dentro y fuera de la escuela. ${ }^{4}$ En este contexto -además de la cultura política, el espacio y la opinión públicos- se empezaron a estudiar como objetos educativos los catecismos políticos y religiosos, la oratoria sagrada, la pastoral cristiana, los manuales de urbanidad y los libros escolares de los siglos XIX y XX. ${ }^{5}$

Sin embargo, aunque desde entonces el interés que más ha predominado tiene que ver con el papel de la historia, el civismo y la lectura en la configuración de la identidad nacional, la formación de los ciudadanos o el nacimiento y adopción de nuevos códigos de conducta, generalmente no hay una consideración de fondo sobre el sentido de la escuela en la Sobre la cultura escolar y su importancia, Juliá, "La cultura escolar", pp. 131-153. En torno a un registro sumario de las cuestiones que aborda la historia del currículum, Dussel, "Introducción", pp. 7-10. En cuanto al nuevo sentido de la historia social del currículum y su impacto en la historia de las disciplinas escolares, Cuesta Fernández, Sociogénesis, pp. 9-25. Acerca de los libros escolares como fuente histórica y las principales tendencias en este campo de la investigación: Johnsen, Libros de texto; Choppin, Manuels Scolaires; Escolano Benito, "La politique du livre scolaire", pp. 2745; Choppin, "L'histoire des manuels scolaires"; Choppin, "Pasado y presente de los manuales escolares", pp. 107-141. escolares, en Choppin, "Prólogo", pp. 13-19; Choppin, "Los manuales escolares", pp. 13-37. El proyecto Patrimonio Escolar-Manuales Escolares (Patre-Manes) fue gran impulsor de este un nuevo campo de investigación. Acerca de su importancia, Ossenbach "La Red Patre-Manes", pp. 145-153; Ossenbach "La investigación sobre los manuales escolares", pp. 195-203. ga, "Making Citizens"; Herrejón Peredo, Del sermón al discurso cívico; Roldán Vera, "Making Citizens"; Sagredo Baeza, "Actores políticos", pp. 501-538; Torres Septién, "Notas sobre urbanidad", pp. 89-111. 
modernidad, pero tampoco sobre el conocimiento escolar en tanto práctica histórica y cultural situada. ${ }^{6}$ Pocas veces la historia de la escuela y la escolarización se concibe dentro del régimen moderno de historicidad que le es propio y como parte del proceso civilizador que conlleva históricamente grados relativamente altos de autodisciplina y de pacificación interna en la sociedad.7 A partir de un "raro consenso transcultural", la mayoría de quienes se ocupan de la escuela no investigan sus orígenes ni cuestionan su condición histórica, su carácter y su papel en la sociedad moderna, ni, aún más, sus alcances. ${ }^{8}$ En consecuencia, no hay una historia crítica de la escolarización ni tampoco un reconocimiento a los pensadores que más han influido en su desarrollo. ${ }^{9}$

En México, mientras en los setenta y ochenta se realizaron diez estudios, en los primeros cinco años de los noventa la cifra aumentó a 53. Véase Guzmán Batalla, "Consideraciones", pp. 47-66. Sobre el despliegue institucional de nuevas temáticas: Meníndez Martínez, "La historia de la educación en México", pp. 151-164. En la perspectiva de Norbert Elias, mantener "una postura civilizatoria en una sociedad requiere un grado de autodisciplina relativamente alto y requiere también algo más: es necesario un alto grado de pacificación en la sociedad". Elias, El proceso de la civilización, p. 141. El régimen de historicidad no sólo es una manera de articular pasado, presente y futuro, sino también una forma de aprehenderlo, decirlo, ordenarlo y darle sentido. Hartog ubica el régimen moderno de historicidad entre las simbólicas fechas de 1789 y 1989. En éste la esperanza se tornó hacia el futuro y el presente fue percibido como inferior al porvenir. ponde a Gimeno, citado por Mateos Montero.

El proyecto intelectual de Michel Foucault, por ejemplo, ha tenido mayor fortuna en el ámbito anglosajón y en países como España y Argentina. Para el ámbito anglosajón, Viñao Frago, "La escuela y la escolaridad", p. 35. En cuanto a España, Galván ofrece una visión global (Galván, "La recepción académica de Michel Foucault", pp. 101-127) y asimismo destaca las contribuciones de Julia Varela en Galván, De vagos y maleantes, pp. 164-190. La misma Julia Varela menciona sus contribuciones en "Conocimiento, poder y subjetivación", pp. 140-144. En España existe un grupo de historiadores como Raimundo Cuesta, Juan Mainer y Julio Mateos que reivindica y alienta en la Federación Icaria el pensamiento crítico foucaultiano y el de aquellos pensadores (Marx, Weber, Bourdieu, etc.) que "ejercieron una concienzuda genealogía del presente para desvelar las relaciones de poder que naturalizaron tales verdades, así como los mecanismos y dispositivos reguladores, las prácticas sociales e institucionales y todo tipo de invenciones que generan históricamente la vida social". En Argentina destacan las investigaciones de Marcelo Caruso, Inés Dussel y Pablo Pineau. 
Sobre esta base, la epistemología social de la escolarización concibe la historia del currículum como la historización de un conocimiento particular que enuncia reglas y pautas a cuyo través "razonamos" sobre el mundo y nosotros mismos, pues lo aprehendido en la escuela no sólo tiene que ver con qué hacer y qué saber. ${ }^{10}$ Aprender "gramática, ciencias, matemáticas o geografía son también disposiciones de aprendizaje, conciencias y sensibilidades acerca del mundo". ${ }^{11}$ Usar un lenguaje es aprender una forma de vida, significar acciones y prácticas humanas, escribió Wittgenstein. ${ }^{12}$ Por tanto, si aún hoy en la escuela, además de trasferir saberes regulados se ejercen distintas labores de socialización -a cuyo través se interiorizan y asumen como propios discursos y prácticas de vida-, en los orígenes de la modernidad como proyecto unos y otras fueron fundamentales para la construcción de un sujeto civilizado y de un ciudadano moderno. ${ }^{13}$

En México, un momento importante para rastrear al mismo tiempo el nacimiento de la escuela moderna y los orígenes de la formación cívica y moral se ubica en el ocaso de la época colonial y las primeras décadas del siglo XIX, toda vez que "la sociedad política" y el Estado se propusieron establecer un nuevo imaginario social que tuvo en la escuela a uno de sus principales agentes para estructurar nuevas identidades individuales y colectivas. ${ }^{14}$

Este trabajo subraya en su conjunto la importancia de una historia del currículum vinculada con la epistemología social del conocimiento; es decir, "se trata de hacer hincapié en la inserción relacional y social del saber en las prácticas y los problemas del poder". ${ }^{15}$ En primer lugar,

10

11

12

$$
\text { (a) }
$$

$$
\text { subsis }
$$$$
\begin{aligned}
& \text { y los regímenes de verdad. Véase Popkewitz, Sociología de las reformas educativas, } \\
& \text { pp. 27-28. }
\end{aligned}
$$ 
tiene el propósito de mostrar brevemente la genealogía de la escuela y su estrecho vínculo con la modernidad; en segundo término, le interesa subrayar el entramado sociopolítico que propicia el surgimiento de la educación cívica y moral en México y, finalmente, al describir y analizar los libros escolares y las prácticas en la escuela, su objetivo es destacar el interés de las instituciones educativas por configurar un sujeto civilizado y un ciudadano moderno, considerando que lo que en las primeras décadas del siglo XIX se concebía como conocimiento legítimo enfatizaba la primacía de lo moral sobre lo cognitivo. ${ }^{16}$

En esta medida, el sentido de la formación cívica y moral se articula con el propio de la institución escolar, que asimismo se convierte en una entidad constructora de subjetividades y en una agencia básica de intervención social, en sintonía con la cosmovisión moderna y el quehacer de otras instituciones disciplinarias como la familia, el hospital, el cuartel y la fábrica. ${ }^{17}$ Es precisamente en estas instituciones donde las generaciones jóvenes internalizan ideas, sentimientos, creencias, valores y actitudes, pero también es ahí donde nacen y se configuran las reglas sociales necesarias para la modernización económica y política de las sociedades que, asimismo, impulsa el Estado liberal como un organismo autónomo dentro de la sociedad moderna.

\section{La genealogía de la escuela y la educación cívica y moral}

Desde el siglo XIX, un espacio social donde, sin confundirse, se entrecruzan la constitución histórica de la ciudadanía y los modos históricos de subjetividad es la escuela, una institución de y para la modernidad, que no tiene elementos en común con otras instituciones educativas del pasado y que en la mayoría de los casos se impuso a través de complejas operaciones de negociación y oposición frente a otras entidades formativas. ${ }^{18}$

16

En torno a la primacía de lo moral sobre lo cognitivo en el antiguo régimen, Mendiola, Retórica, comunicación y realidad, pp. 241-243.

Según Pineau, a ser moderno "se aprendía, principal pero no exclusivamente, en la escuela. Ella enseñaba a actuar sobre el mundo de acuerdo con ciertas premisas y matrices que se articulaban con los efectos de otras instituciones similares". Pineau, "A modo de introducción", p. 21. Sobre el despliegue de la urbanidad y la educación cívica como disciplinas escolares en los dos últimos siglos, Benso Calvo, "La urbanidad y la educación cívica", pp. 35-55. Acerca del surgimiento de las asignaturas en la escuela, Chartier y Hébrard, “Alfabetismo y escolarización”, pp. 274-275.

Pineau, “¿Por qué triunfó la escuela?”, p. 31. 
Básicamente, los orígenes de esta institución tienen que ver con la constitución progresiva de la infancia, el nacimiento de la pastoral cristiana del siglo XVI, la definición conceptual de clase y currículum en los siglos XVII y XVIII y el desarrollo del Estado absolutista durante el antiguo régimen. ${ }^{19}$

En el ocaso de la Edad Media, una pléyade de moralistas insistió en la configuración de la infancia como un estadio específico en la vida humana que para el siglo XVII desembocaría en el sentimiento moderno de familia..$^{20}$ En paralelo, si a partir del siglo XVI el aprendizaje tradicional se fue sustituyendo por la escuela, fue la pastoral cristiana la que la proveyó de un conjunto de prácticas a cuyo través empezó un largo proceso de subjetivación. ${ }^{21}$ Aquí, lo que la pedagogía cristiana aportó para el desarrollo de los sistemas escolares de masas fue más importante de lo que parece: contribuyó a "organizar las rutinas, las prácticas pedagógicas, las disciplinas personales y las relaciones interpersonales que más tarde acabarían por formar el núcleo de la escuela moderna". ${ }^{22}$ Precisamente, gracias a los conceptos de clase y currículum 1) se concibe el curso escolar como una entidad organizada en torno a la adquisición de conocimientos definidos; 2) se fortalece el principio de un método pedagógico progresivo, y 3) se proyecta la escuela como una institución disciplinaria. ${ }^{23}$

En cuanto al Estado absolutista, éste consiguió organizarse por encima de las disputas políticas y religiosas mediante la pretensión del monopolio legítimo de la coacción física para el mantenimiento del orden social y el establecimiento de un riguroso orden administrativo. ${ }^{24}$ Su autonomía ética significó el establecimiento de una diferencia teórica entre el "ciudadano" (cuyo acatamiento de la ley era la condición para lograr la paz social) y el "hombre" (que podía seguir libremente la luz de su conciencia, siempre y cuando ésta no interfiriera con su deber público para con la ley), la cual condujo a dos modos distintos y autónomos de comportamiento y también dio pie a la existencia de un ciudadano escindido entre sus derechos individuales y políticos. ${ }^{25}$

19

Pineau describe y analiza 17 piezas que se fueron ensamblando para generar la escuela moderna. Aquí sólo señalamos las fundamentales. Pineau, "¿Por qué triunfó la escuela?", pp. 31-39.

20

21

22

23

24

25 Ariès, El niño y la vida familiar, pp. 539-544.

Hunter, Repensar la escuela, pp. 59-63, 66.

Hunter, Repensar la escuela, p. 82.

Hamilton, "Orígenes", pp. 201-222.

Anderson, El Estado absolutista, 27-28; Hunter, Repensar la escuela, pp. 66-67.

Hunter, Repensar la escuela, pp. 68-69. 
Promotora de la modernidad y auspiciada por ella, la novedad de la escuela moderna consistió en integrar en el salón de clases ambas conductas: la que se correspondía con la gobernación del Estado, a través de la razón como ejercicio crítico, y la relativa a la perfección personal de sí frente a los otros, mediante un conjunto de técnicas referidas al control de sí mismo. ${ }^{26}$ En consecuencia, el mayor propósito de los sistemas escolares de los siglos XIX y XX fue proveer y fomentar los saberes necesarios para que los individuos se comportaran como criaturas "dueñas de sí mismas" (racionales) en las esferas pública y privada; lo cual supuso un acontecimiento radical, por cuanto que, por un lado, la administración social de la libertad individual ("gobierno del alma") modificó las sensibilidades y los comportamientos humanos anteriores y, por otro, conllevó al fortalecimiento de la libertad en tanto práctica individual colectiva de participación política en un ámbito de suyo reducido. ${ }^{27}$

De hecho, durante los siglos XIX y XX la gobernación de los individuos y la sociedad no se lograría sólo mediante la organización, los procedimientos y los procesos formales de las instituciones, sino a través de la administración social de la libertad (disciplina interior) y el ejercicio administrado de ésta en la esfera pública (participación política). ${ }^{28} \mathrm{Si}$, además, consideramos que el currículum es una tecnología disciplinaria que se orienta no sólo hacia cómo el individuo debe actuar, sentir, hablar y "ver" el mundo, sino también a cómo debe verse "a sí mismo", es de subrayar cómo en la escuela (campo de práctica y reproducción cultural) se fortalecen la disciplina interior (coacciones internas) y también las obligaciones del individuo para con los suyos, la sociedad y el Estado (coacciones sociales o exteriores). ${ }^{29}$ Así pues, la tarea de la escuela moderna tendrá como fin básico estructurar nuevas subjetividades, desde las formas personales de comportamiento en sociedad hasta la identidad política y social del ciudadano. De ahí que el nacimiento de la educación moral y de la educación cívica, como asignaturas específicas, se confunda por antonomasia con la tarea misma de la escuela. ${ }^{30}$

26

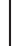

Morey, "Introducción”, pp. 35-36.

Ciertamente en el siglo XIX el ejercicio de la ciudadanía estuvo muy limitado.

Popkewitz "Infancia, modernidad y escolarización", pp. 19-28; Pineau, "Premisas básicas de la escolarización", pp. 46-47.

Popkewitz, "La producción de la razón", pp. 147-148.

En el siglo XVI el hombre educado tenía gustos refinados, era aristócrata. Pero, “¿qué significa ser aristócrata? Pues saber hablar como ellos, saludar como ellos, en una palabra, ser como ellos". Mendiola, Retórica, pp. 134, 220. La educación humanista era símbolo de prestigio y distinción. 
En el antiguo régimen, los manuales de urbanidad y buenas maneras habían estado ligados a la depuración y al refinamiento de la nobleza y la burguesía en ascenso, pero en los siglos XIX y XX la novedad de esos libros estribará en que aparecen insertos en el ámbito escolar, donde serán enseñados a comunidades étnicas y grupos sociales ajenos a esas prácticas. Su propósito, civilizarlos: ellos, los escolares, deben procesar en su yo interno "coacciones otrora sociales... para que cada individuo conciba como natural su propio comportamiento". ${ }^{31}$ Pero, si las prácticas de la escuela y los manuales de urbanidad y buenos modales tuvieron un papel destacado en la represión de los instintos y en el surgimiento de una nueva sensibilidad individual y colectiva, después de la Revolución francesa los catecismos políticos contribuirán no sólo a la modernización política de la sociedad y de las elites, sino serán un útil complemento para comprometer la lealtad de las generaciones jóvenes al Estado liberal, no ya a la monarquía.

De esta guisa, en los albores del siglo XIX la formación cívica y moral se concibió como necesaria e indispensable en todas las naciones "progresistas", civilizadas. Más que como un espacio para difundir nuevos conocimientos, la escuela fue vista como un dispositivo para extender nuevos preceptos morales y nuevos códigos participativos en la vida de los individuos y las comunidades; al gobierno del alma debería sumarse el ejercicio de la libertad, en tanto práctica individual y colectiva. ${ }^{32} \mathrm{Si}$ el conocimiento es un campo de prácticas culturales, el propósito de los saberes transmitidos a través de los manuales escolares y las rutinas que se suceden dentro y fuera de la escuela sería construir un nuevo imaginario social donde los seres humanos, convertidos en individuos y ciudadanos, fuesen capaces de comportarse "racionalmente", tanto en el espacio privado como en el público. ${ }^{33}$

Durante el siglo XIX, los nuevos estados iberoamericanos encontrarán en la educación cívica y moral una manera de ordenar e institucionalizar "la nueva lógica de la civilización y, por lo tanto, de hacer realidad el sueño modernizador" de las repúblicas civiles e ilustradas: formar individuos y ciudadanos, hombres de provecho, según el nuevo orden social derivado de la independencia. ${ }^{34}$ No obstante, la formación de individuos y ciudadanos como sujetos de derecho sólo sería posible "dentro del marco de las instituciones disciplinarias y dentro de un campo de identidades

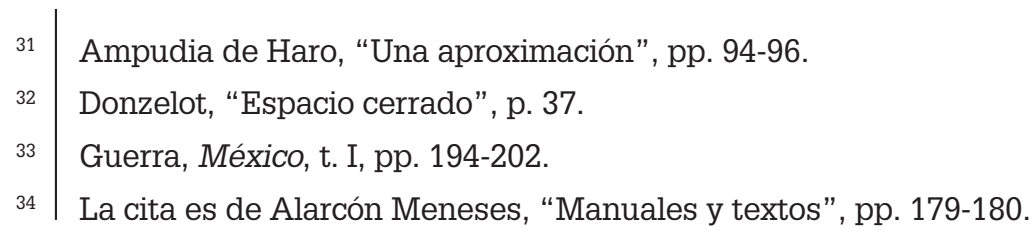


homogéneas y estandarizadas". La escuela sería la formadora de ciudadanos honrados y buenos cristianos, seres con una identidad ecuménica, ajena a toda diferencia y, en contraste con la realidad social, diversa.

\section{El entramado sociopolítico de la educación cívica y moral en México}

En el último tercio del siglo XVIII, la Corona se propuso poner en manos del Estado el monopolio legítimo de la violencia. Contra la idea de que el gobierno radica en los poderes y privilegios (fueros) de las corporaciones (gremios, pueblos), a partir del ascenso de Carlos III la Corona y sus voceros intentaron legitimar el origen divino de la autoridad sobre nuevas bases. ${ }^{35}$ Así, desde el púlpito se comenzó a configurar un nuevo modelo de vasallo, sumiso y obediente a los dictados de la Iglesia y el poder civil. En el plano doctrinal ello significó subrayar la importancia de los mandamientos sobre los pecados capitales, pues aquéllos comportaban virtudes (amar, honrar, obedecer) y no ya pasiones que debieran sofocarse. Frente a la coacción social externa, los mandamientos subrayan "las relaciones del individuo con Dios, con la familia y con el prójimo; sus mensajes... sugerían el respeto a la autoridad, la reforma de las costumbres, el bienestar social y el amor y caridad como medios para alcanzar la gracia". ${ }^{36}$ Desde el control del esfínter y el cuidado corporal hasta la retícula del espacio urbano, en el ocaso del régimen colonial las políticas públicas desplegadas por la monarquía se propusieron fabricar cuerpos ordenados, limpios, dóciles, obedientes. Ésa fue una de las principales tareas que los ilustrados y el Estado asignaron a la escuela pública. En Nueva España estas orientaciones fueron más evidentes cuando menos desde la última década del siglo XVIII, sobre todo a raíz de la gran crisis agrícola de 1785 y frente al propio impacto de la Revolución francesa. De hecho, en 1810 había numerosas escuelas a lo largo y ancho de la Nueva España, aunque no siempre en manos de las autoridades reales. ${ }^{37}$

Por otro lado, el desarrollo de la imprenta en las últimas décadas del siglo XVII produjo un proceso continuo de secularización y politización,

\footnotetext{
35 Sobre todo en la filosofía tomista y en los principios religiosos de Agustín de Hipona. Márquez Carrillo, “¿Quién funda ciudades y reinos?”, pp. 140-150; Guerra, Modernidad e independencias, pp. 28-29. Guerra, Modernidad e independencias, pp. 277-279. Hacia 1803, por ejemplo, los 4088 pueblos de indios de la Nueva España tenían 1015 escuelas bajo su cuidado. Tanck de Estrada, Pueblos de indios, pp. 168-189, 286.
} 
que se incrementó en las últimas décadas del siglo XVIII. ${ }^{38}$ Por ende, si entre 1790 y 1824 la extensa red escolar y los procesos de alfabetización en la Nueva España propiciaron un cambio general de mentalidad -o mejor aún su hibridación con el pasado, que dio pie a una república "barroca", católica, tradicional-, en ese mismo lapso la participación "ciudadana" del común tuvo su concreción inicial en la elección de los primeros ayuntamientos constitucionales (1812-1814) y, sobre todo entre 1820 y 1824, defendiendo los intereses de los pueblos que encontraron en los ayuntamientos y en la ciudadanía nuevas formas corporativas para sobrevivir; pero igual, entre la consumación de la independencia y la primera República, las oligarquías regionales hicieron un pacto entre sí y una alianza con las clases medias y populares, ya que su preocupación era mantenerse en el poder. ${ }^{39}$ En ese lapso, empero, mientras se alentaba la participación política de las masas y la formación de la opinión pública, el poder oligárquico se fortalecía en los estados menguando el gobierno de la federación, que pugnaba por una nueva República, apoyada exclusivamente en los principios de la política moderna. ${ }^{40}$ Transformados la comunidad local -indígena o no- y los individuos de ocupación "honesta y honorable" en fuente de derechos políticos, una y otros tuvieron distintas razones para preocuparse por la formación de las nuevas generaciones. ${ }^{41}$

Por vía de los hechos, en el imaginario colectivo de la época la construcción de la nación aparecería como un proceso incluyente donde lo heterogéneo y la ausencia de cohesión en ella se irían esfumando por obra de las instituciones y de una educación orientada a la formación de ciudadanos y hombres virtuosos. ${ }^{42}$ La escuela se concibió, entonces, como referente obligado y necesario para difundir las máximas del liberalismo (que no sin conflictos iban prosperando en distintos espacios y prácticas de sociabilidad), afirmar los principios de la religión católica y extender al pueblo civilizadas formas de convivencia social. Su tarea era formar "hombres, ciudadanos y cristianos", en referencia primera a la Consti-

38

39

40

Guerra, Modernidad e independencias, pp. 276-296.

Hale, El liberalismo mexicano, p. 82.

Lempérière, "De la nación corporativa", pp. 320-326; González Oropeza, "Características", pp. 413-414.

Hale, El liberalismo mexicano, pp. 82-83. En las primeras décadas del siglo xIX, la participación popular tuvo insospechados cauces. Baste recordar que en 1812 había 54 ayuntamientos, pero para 1821 eran casi un millar; en cuanto a las diputaciones, éstas pasaron de seis en 1820 a 14 en abril de 1821.

Quijada, “¿Qué nación?”, pp. 306-314. La autora se refiere al proceso hispanoamericano. 
tución de Cádiz (1812), que ordenaba establecer escuelas de primeras letras en todos los pueblos para enseñarles a los niños, además de leer, escribir y contar, el catecismo de la Iglesia y una breve explicación de las obligaciones civiles. ${ }^{43}$ Por eso, durante la primera República, con base en la Constitución de 1824, se profundizaron en las entidades federativas los múltiples esfuerzos de escolarización y alfabetización, al mismo tiempo que se impulsaba el ejercicio de una ciudadanía sin cortapisas, ya que el sufragio masculino fue casi universal, aunque el ejercicio del poder quedó en pocas manos. ${ }^{44}$ En las aulas, junto a la formación cívica estarían las cuestiones de moral y urbanidad, cuya dirección se fue afinando de 1826 a 1832. En 1833, sin embargo, desaparecerían éstas del currículum; ahora se trataba de fortalecer los principios rectores de la ciudadanía, la educación cívica de las nuevas generaciones. ${ }^{45}$

El problema es que, a partir de 1833, los reformadores en el gobierno federal "impusieron o señalaron cambios fundamentales en la vida política, social, económica y cultural de la nación", con lo cual consiguieron que instituciones (Iglesia, ejército), grupos, sectores y aun las propias oligarquías regionales se unieran en su contra, no sólo temerosos de un levantamiento social, sino de que se otorgara a las "clases peligrosas" más derecho al voto y se permitiera con ello que el poder cayera en manos de la "baja democracia" que, amotinada en 1828 con motivo de las elecciones, había hecho temblar a las "clases acomodadas". ${ }^{46}$ Así, la alianza de las oligarquías regionales con las clases medias y populares fue entrando en una nueva fase. El propósito de formar una "nación cívica" iría mudando hacia el interés por establecer una "nación civilizada", cuya imagen desde 1835 se fue asociando paulatinamente con la exclusión "necesaria" de los elementos que no se adaptasen a ella. ${ }^{47} \mathrm{Si}$ en diciembre de 1835

43

Meneses Morales, Tendencias, p. 72.

Tanck de Estrada, "La alfabetización", pp. 124-127. La Constitución de 1824 estableció que para ser diputado federal se requería contar con un capital de ocho mil pesos de bienes raíces o una industria que produjera diez mil pesos al año (artículo 20). http:// www.juridicas.unam.mx/infjur/leg/conshist/pdf/1824.pdf.

En 1826 se enseñan Máximas de moral y educación; en 1827, Urbanidad. Pero en 1832 la materia es más específica: Reglas de urbanidad. Asimismo, el currículum de este año muestra un carácter más definido. Junto a las Reglas de urbanidad aparecen Principios elementales de Religión y Nociones necesarias de la Constitución. Meneses Morales, Tendencias, pp. 85, 89, 104.

Costeloe, La República central en México, pp. 51-57.

Quijada, “¿Qué nación?”, pp. 2003, pp. 306-314. Para Hispanoamérica, el proceso lo sitúa la autora a mediados del siglo. 
se instituyó que sólo serían ciudadanos los mexicanos que tuvieran "una renta anual lo menos de cien pesos, procedentes de capital fijo o mobiliario, o de industria y trabajo personal, honesto y útil a la sociedad", las leyes constitucionales de 1836 establecieron que para ocupar cargos de elección o representación se requería haber cumplido cierta edad y tener una renta anual de por lo menos la cantidad estipulada para el cargo. ${ }^{48}$

No es que este modelo pusiera en duda la fuerza modificadora de las instituciones y la educación. Contra el "espíritu de partido", si viejos atavismos impedían que todos los ciudadanos se hicieran responsables de su destino, aparecería una democracia tutelada por los "hombres de bien" (liberales, conservadores, moderados), unidos contra cualquier extremismo. ${ }^{49}$ La democracia se conseguiría en un proceso de largo aliento. ${ }^{50}$ Más importante que la educación cívica sería la educación moral, la educación de las costumbres, para pulir a la plebe y mantenerla en "el temor de Dios" y la obediencia a las autoridades todas. La "primavera democrática" de la Primera República entraba en una nueva fase, para cuyo estudio habría que vincular la doctrina, la norma y las prácticas políticas de la época.

\section{El sentido de los discursos y las prácticas escolares}

En esta medida, ¿qué papel desempeñó la escuela y cuál fue el significado de los saberes transmitidos? En el ocaso de la Nueva España y los primeros años del México independiente, los niños pobres de las escuelas gratuitas aprendían en silencio, repartidos en estancias separadas o en un mismo espacio, dividido en varias escuelas o secciones y bajo el cuidado personal de auxiliares o curadores de menores. La sala de lectura constaba de cuando menos dos tendidos de gradas, una para los alumnos y otra para los auxiliares que se ponían a corregirlos. El cuarto de escribir tenía mesas y bancas, muestras y lemas -a veces también pinturas y grabados- colgados en las paredes, que los niños copiaban en pizarras. Las

48

50 Hale, El liberalismo mexicano, pp. 240-254. 
clases, de lunes a sábado, por la mañana y por la tarde, empezaban con varias oraciones. Luego, el maestro repartía libros, distribuía quehaceres, y más tarde comenzaba a explicar y a pedir cuentas de las tareas asignadas a cada cual, conforme al grado particular de avance. ${ }^{51}$ No había, en consecuencia, una idea de clase o grupo escolar.

En el aula, una invención del siglo XVI, predominaban no sólo los castigos corporales y una disciplina estricta sobre el cuerpo, mediante los controles continuos y específicos de los curadores y el maestro, sino que la corrección se inscribía en la actividad misma del aprendizaje y desempeñaba cuando menos la función de gratificar y sancionar. Unida a la rigidez de las normas, se iba organizando una microeconomía de los premios y de los ejercicios escolares que "facilitarán una diferenciación continua y una penalidad que no se dirige tanto a los actos en sí, cuanto a los individuos mismos", y esta penalidad jerarquizante permitirá distribuir a los alumnos según su conducta y aptitudes, con lo cual, frente a un sistema de igualdades formales y una aparente homogeneidad, se resaltan las diferencias, que a su vez adquieren una nueva dimensión por el examen, un procedimiento "objetivo" para clasificar, calificar y premiar o castigar a los alumnos. ${ }^{52}$ Junto a la disciplina extrema, la modalidad en el control del cuerpo implicó "una coerción ininterrumpida, constante, que vela sobre los procesos de la actividad más que sobre su resultado y se ejerce según una codificación que reticula con la mayor aproximación el tiempo, el espacio y los movimientos". ${ }^{53}$ Puesto que el poder se construye y funciona a partir de poderes, de multitud de cuestiones y efectos de poder, la disciplina no sólo forma nuevos cuerpos, los encauza para adorar a Dios, honrar y obedecer a sus padres y superiores... a someterse a las leyes humanas y divinas, a "formar unos hombres de bien y leales vasallos". ${ }^{54}$

Por otra parte, en el método de los padres escolapios están integrados tres procedimientos de la escuela moderna: la enseñanza propiamente dicha, la adquisición de conocimientos por el ejercicio mismo de la actividad pedagógica y una observación recíproca y jerarquizada, que se convertirá en un mecanismo que le es inherente y multiplica la eficacia

51

Tanck de Estrada, La educación ilustrada, pp. 220-224; Reyes Morales, "Un día de clases en la época colonial", pp. 26-29. "Sobre el establecimiento de una escuela gratuita en San Marcos. 1828”. AAP. Escuelas, vol. 67, leg. 762, f. 198.

Tanck de Estrada, La educación ilustrada, pp. 230-231; Varela, "Elementos", pp. 179-

180; Foucault, Vigilar y castigar, pp. 189-192.

Foucault, Vigilar y castigar, pp. 189-192.

Foucault, Microfísica del poder, pp. 157-158; Alonso Rodríguez, Catón español político christiano, pp. VIII-IX. 
de la institución escolar. ${ }^{55}$ Luego, gracias al método de enseñanza mutua o lancasteriana, estos procedimientos comenzarán a tener mayor influjo en nuestro país durante la Primera República. ${ }^{56}$

Introducido en la Nueva España por los padres betlemitas y puesto en práctica en las ciudades de México y Puebla antes de consumarse la independencia, en este método los niños más aventajados enseñaban a sus compañeros, pero tenían que presentarse media hora antes para recibir instrucciones, formar a los alumnos, pasar revista de aseo y hacerse cargo de un grupo de diez niños, que según su aprovechamiento en el mismo espacio se colocaban una y otra vez en distintas posiciones o semicírculos. El eje central de esta empresa educativa era el orden, la disciplina, la emulación y el esfuerzo individual, más -en menor medidauna lógica de premios y castigos, incluso corporales. Los instructores o monitores llevaban la escuela; el maestro y director se limitaba a enseñar al grupo de vanguardia, a observar la disciplina y el orden de la sala y a recibir las quejas de los instructores. Una sola persona podía dirigir una escuela de hasta de 500 alumnos, con la ventaja de que las habilidades de leer, escribir y contar se aprendían de manera paralela, masiva y en menor tiempo. ${ }^{57}$ Ahora, el salón de clases era un espacio amplio con bancas y mesas alineadas una tras otra, cada banca con capacidad para diez niños. Al frente estaban la tarima del maestro y mesas de arena para los alumnos principiantes que se dedicaban a escribir y hacer números; en los costados, "semicírculos" para lectura y presidía sobre la tarima una imagen religiosa.

A diferencia del método uniforme de los padres escolapios, en este tipo de escuela predominaban la disciplina y la puntualidad militares, nunca el ejercicio democrático, que era lo que supuestamente se exaltaba en el contexto social. Todas las actividades y los movimientos estaban cronometrados para infundir en los alumnos amor al trabajo, espíritu de orden, economía y previsión, disciplina, obediencia rápida y ciega a las normas sin que mediase explicación racional alguna. ${ }^{58} \mathrm{Al}$ asignar lugares individuales, la escuela hizo posible el control de cada cual y el trabajo simultáneo de todos y garantizó el acatamiento de relaciones de poder específicas, indispensables para la marcha del Estado moderno;

\footnotetext{
55 Varela, "Elementos", pp. 179-181; Foucault, Vigilar y castigar, p. 181. Guzmán Hernández, Zacatlán, pp. 1-4.

Tanck de Estrada, La educación ilustrada, pp. 180, 232-237; Plan de escuelas de primeras letras, $\mathrm{s} / \mathrm{p}$.

58 Guzmán Hernández, Zacatlán, pp. 11-12; Tanck de Estrada, La educación ilustrada, pp. 180, 232-235.
} 
también inculcó hábitos personales de disciplina y preparó a la futura fuerza de trabajo. ${ }^{59}$

Cara de la misma moneda, desde el Siglo de las Luces el modelo romano tuvo un doble papel: "bajo su apariencia republicana, era la institución misma de la libertad; bajo su faz militar, era el esquema ideal de la disciplina". ${ }^{60}$ De esta suerte, mientras por una parte se insistía en el aprendizaje y el cultivo de las virtudes cívicas, el método de los padres escolapios y el sistema lancasteriano enseñaban la práctica de la obediencia, que del mismo modo se veía reforzada por los contenidos curriculares explícitos, el magma religioso e intelectual de la época y la persistencia de los métodos pedagógicos del periodo colonial, pues si bien hubo un crecimiento en la escolarización y la alfabetización durante las primeras décadas del México independiente y se habló de la apertura de la escuela lancasteriana en distintas partes del país -lo que lleva a una oleada educativa modernizadora-, un crítico de la época decía: "sucede con la enseñanza mutua lo que con ciertas piedras preciosas que cree uno ver en todas partes, porque en todas partes las imitan, y las que sin embargo no encuentra sino rara vez" ${ }^{61}$ Por todo ello, frente a la exaltación de las virtudes cívicas y religiosas, la obediencia sería un discurso y una práctica comunes, asimismo vinculados con el control de las emociones. En este contexto, ¿qué reflejan los libros y las prácticas escolares?

Desde el ocaso del régimen colonial, los manuales de urbanidad y buenas maneras y en general los ritos escolares se encaminaban a la modificación de la conducta a partir de un nuevo discurso donde aparecían imbricados el orden jerárquico y la relación saber-poder, según era de leerse en una plana que en la clase de escritura copiaban los alumnos del profesor José María Herrera, en Puebla, hacia 1812:

Al que más sabe es a quien por razón y por naturaleza le pertenece el mando. El que no sabe sólo debe servir y obedecer; por eso al hombre le dio Dios el imperio sobre los demás animales porque el hombre conoce más y sabe más que ellos. ${ }^{62}$

Pero no nada más eso, el individuo que conoce y sabe es un ser racional y debe reflejarlo en sus hábitos. "El hombre que en su niñez y

59

60

61

62

"Sobre licencia a don José María Herrera para poner una escuela. 1812." AAP. Escuelas,

Foucault, Microfísica del poder, p. 157

Foucault, Vigilar y castigar, p. 150.

Guénot, Plan de educación elemental, p. 6. vol. 67, leg. 754, ff. 67- 68. 
juventud ha recibido buena educación, decía el Catón español político christiano, manda a su cuerpo, arregla sus movimientos, detiene los ímpetus de su cólera, modifica sus pasiones". ${ }^{63}$ El Catecismo de urbanidad civil y cristiana señalaba, de igual modo, que los vicios más opuestos a la cortesía y urbanidad son "la afección estudiada, hija de la soberbia; la arrogancia y vanidad; el desasosiego y la locura impertinente". Por eso, en el salón de clases, "nunca se enoje con alguno, ni amenace con ira y soberbia". Si se le manda tener cuidado del grupo, "hágalo por obedecer sólo y ayudar al buen orden, sin pasión ni venganza". A todos trate "con afabilidad y cortesía, evitando los excesos de llaneza disoluta y severidad afectada". En el salón de clases el niño debía expresar "en la postura de sus vestidos, pies, manos, ojos y todos sus movimientos, el respeto, sumisión, obediencia y buena crianza". ${ }^{64}$ Un ser refinado, pulido.

El niño civilizado se comportaba conforme al código moral establecido por la aristocracia medieval y del antiguo régimen, recibía la enseñanza de los buenos modales (urbanidad). En ella, la obediencia a los padres era una metáfora para referirse a todos los mayores, ya que san Pedro ordenaba obedecer, incluso a los "díscolos", pues "la autoridad con que mandan es del mismo Dios". ${ }^{65}$ En la obra de Félix Mendarte para la enseñanza mutua, difundida en varios estados de la República como Veracruz, Puebla, Coahuila y Texas, se leía:

¿Quién... honra a sus padres? El que los obedece socorre y reverencia./ [...]-¿Quiénes otros son entendidos por padres a más de los naturales? Los mayores de edad, saber y gobierno./ -Los casados con sus mujeres, ¿cómo deben haberse? Amorosa y cuerdamente como Cristo con la Iglesia./ -Y las mujeres con los maridos, ¿cómo? Con amor y reverencia como la Iglesia con Cristo./ -Y los amos con los criados ¿cómo? Como con los hijos de Dios./ -Y los criados con los amos ¿cómo? Como quien sirve a Dios en ellos. ${ }^{66}$

63

64 ff. 66. El libro fue publicado por su autor en 1828. Véase Mendarte, Arte para la primera enseñanza. "La obra de Mendarte sobre el sistema mutuo. 1828". AAP. Escuelas, vol. 68, leg. 765, f. 31. Lardizábal y Uribe, Discurso sobre las penas, p. 27; Díaz y Tirado, Sermón panegíricomoral, pp. XVI-XVII.

"La obra de Mendarte sobre el sistema mutuo. 1828". AAP. Escuelas, vol. 68, leg. 765, 
En el mismo sentido, el Catecismo histórico del abad Claude Fleury expresaba:

-¿Cómo debemos honrar a nuestros padres? Aprovechando sus instrucciones y obedeciéndolos./ - ¿Es gran mal irritarlos? Sí, ése es un gran pecado./ -¿Quiénes son nuestros padres espirituales? Los obispos, los sacerdotes y todos aquellos que nos enseñan./ -¿A qué otra cosa nos obliga este mandamiento, [el Cuarto]? A obedecer al Rey y a sus ministros. [...] -¿Qué debemos hacer para evitar el pecado? Huir del ocio y de las malas compañías. ${ }^{67}$

El Catecismo de urbanidad civil y cristiana, por su parte, decía:

-Los hijos con los padres ¿Cómo deben portarse? Con total obediencia y socorro en cuanto sea conducente a su salvación y bienestar: con respeto como a un lugarteniente de Dios; como súbditos de un señor y amantes del más fiel amigo [...] - ¿Y los discípulos con sus maestros? Con amor respetuoso, como hijos de un buen padre e intérprete de la voluntad de Dios. ${ }^{68}$

Podríamos enunciar otros muchos ejemplos de cómo desde los libros escolares el discurso sacralizado de la obediencia se enlazaba con las prácticas educativas. Casi hacia 1835 era lo mismo que se enseñaba a finales de la época colonial, y sin embargo, a partir de 1820 y durante la Primera República habría dos nuevos elementos: la Constitución particular de cada estado -donde en algunos casos se pretendía que los niños aprendiesen a leer- y los catecismos políticos. En este último caso, los alumnos podían aprender lo que es una Constitución y lo que son las leyes, el concepto de ciudadanía y la forma de adquirirla, los diferentes tipos de gobierno, la composición, las obligaciones y los atributos de las Cortes (parlamento), el rey, el consejo de Estado, los tribunales, el gobierno interior de las provincias y los pueblos y, finalmente, la composición y funciones de la fuerza militar española, si se utilizaba para estos menesteres el Catecismo político, arreglado a la Constitución de la Monarquía Española. ${ }^{69} \mathrm{Si}$, por otra parte, se estudiaba en el Catecismo de Repúbli-

67

68

69

Fleury, Catecismo histórico, pp. 139-140.

Delgado de Jesús y María, Catecismo de urbanidad civil y cristiana, pp. 45-46.

D. J. C., Catecismo político arreglado a la Constitución de la Monarquía Española;

Sagredo Baeza, “Actores políticos", pp. 505-506; Tanck de Estrada, "Los catecismos políticos", pp. 70-71.

Letras Históricas / Número 15 / Otoño 2016-invierno 2017 / México / pp. 43-71 / ISSN: 2007-1140 
ca, el aprendiz de ciudadano podría conocer el carácter, soberano, libre e independiente de la nación mexicana, los derechos de los pueblos, la división del gobierno en poderes, la diferencia entre las leyes, políticas civiles y criminales, la existencia de la libertad natural, civil y política, el significado y los alcances de la ciudadanía, los derechos individuales de los ciudadanos (libertad, propiedad, seguridad, igualdad) y los deberes de los ciudadanos, entre ellos ser religiosos, "hombres de bien", respetuosos de las leyes y las autoridades y observantes de las virtudes civiles emanadas de las religiosas. ${ }^{70}$

En cambio, si la perspectiva de enseñanza se situaba en las constituciones particulares de cada estado, el estudiante podía aprender sobre la soberanía y su titularidad, la intolerancia de otra religión que no fuese la católica, apostólica y romana, los derechos individuales de los ciudadanos o su definición puntual -como lo hacían Chiapas, Guanajuato, Michoacán, San Luis Potosí, Sonora y Sinaloa (los dos últimos fundidos en el estado de occidente hasta 1830)-, pero también los derechos políticos del ciudadano. ${ }^{71}$

Los catecismos políticos, entre otras cosas, hacían hincapié en el conocimiento de los derechos civiles, entendidos como aquellos que las leyes de cada sociedad conceden a sus individuos "y que son la libertad, la igualdad, la seguridad y la propiedad". ${ }^{72}$ Nadie con un "modo honesto de vivir" dudaba que los principales y más sagrados derechos de los individuos fueran los concernientes a la seguridad de su persona y bienes, pero en cuanto a la libertad y a la igualdad, El Catecismo político, arreglado a la Constitución preguntaba:

- ¿En qué consiste la libertad? La libertad no consiste como creen algunos ignorantes en que el hombre tenga facultad para hacer cuanto se le antoje, sino en que pueda hacer todo lo que no perjudique a los derechos de otro, y no esté prohibido por las leyes. -La igualdad ¿en qué consiste? En que la ley sea la misma para todos. ${ }^{73}$

El Catecismo político mexicano inquiría:

-¿En qué consiste la igualdad? En que las leyes premian o castigan indistintamente ciertas acciones sin consideración a la persona que

70 Vargas, Catecismo de República; Arredondo López, "La formación de los ciudadanos", pp. 67-87.

71

72

73 Carrillo Prieto, La ideología jurídica, pp. 188-208. Catecismo político mexicano, p. 6; D. J. C., Catecismo político arreglado, p. 11. D. J. C., Catecismo político arreglado, pp. 11-12. 
las ejecuta [...]. Ésta es la idea verdadera de igualdad, debiendo tenerse por quimérica cualquiera otra inteligencia que se dé, y en este sentido es justa, y nadie puede reprobarla; mas ella misma destruiría la sociedad si se le diese la extensión ilimitada, que equivocadamente pretenden algunos. - ¿Por qué? Porque la sociedad no existe sin orden, y no puede haberlo sin que haya un gobierno a quien todos respeten y obedezcan. ${ }^{74}$

\section{Una consideración final}

Tanto en sus discursos como en sus prácticas, la escuela -se pensabapretendía fortalecer el orden social; pero más allá de estos propósitos, ella misma, como sus congéneres de otras latitudes, se propuso configurar en México un sujeto civilizado y un ciudadano moderno. Durante el siglo XIX, en ningún lugar de las constituciones particulares de los estados o de los catecismos políticos se menciona "la existencia en el territorio nacional no sólo de hombres a los que todos llaman indios, que se sienten como tales y que representan la mayoría de la población, sino de verdaderas tribus organizadas que escapan a la autoridad del Estado (mayas, yaquis, tarahumaras, etc.)" ${ }^{75}$ Pese a la gran movilización popular, en el imaginario liberal de la Primera República todo lo que pudiese perturbar la igualdad de los hombres ante la ley estaba prohibido; la propiedad privada e individual, además, era inseparable de la libertad y constituía el fundamento de la sociedad civil. En la escuela pública, los niños no sólo aprendían a disciplinar sus pasiones, también se adentraban en el conocimiento de los casi impracticables derechos civiles o individuales, pues éstos estaban ahí para las elites de poder y las "clases medias"; en el resto de la sociedad éstos estaban restringidos. Su razón de ser en el currículum, sin embargo, era que a su través se pretendía moldear una nueva sociedad y un hombre nuevo. En esos años, ante todo se necesitaba garantizar la independencia del poder colonial y la instauración de

\footnotetext{
74 Catecismo político mexicano, pp. 8-9. La igualdad, escribió José María Luis Mora, “ha sido entre nosotros un semillero de errores y un manantial fecundísimo de desgracias. Por la igualdad se han confundido el sabio con el ignorante, el juicioso y moderado con el inquieto y bullicioso, el honrado y virtuoso ciudadano con el díscolo y perverso; por la igualdad han ocupado todos los puestos públicos una multitud de hombres sin educación ni principios, y cuyo menor defecto ha sido carecer de las disposiciones necesarias para desempeñarlos". Aguilar Rivera, "El veredicto del pueblo", p. 143.

75 Guerra, México, t. I, p. 33.
} 
una nueva legitimidad política. ${ }^{76} \mathrm{La}$ formación cívica y moral -como la historia, la geografía o la lectura- serían a lo largo del siglo XIX la base para construir la nación como una comunidad imaginada donde servir, respetar, honrar, obedecer a los superiores y al Estado, en lugar de la Iglesia, sería una de las pautas para los nuevos súbditos, más que ciudadanos con derechos plenos (las elecciones indirectas se mantuvieron en México desde 1812 hasta 1911). ${ }^{77}$ Durante el siglo XIX, a través de la escuela, "los hombres de bien" y el Estado se encargaron de tutelar la democracia y de formar a los ciudadanos modernos del futuro. Quedan, sin embargo, varias interrogantes; una de ellas tiene que ver con la forma como las generaciones jóvenes de la Primera República asumieron en su edad adulta los derechos individuales, la noción de ciudadanía y la representación política. ${ }^{78}$ ¿Cuánto contribuyó la escuela en este sentido? Aun cuando se ha dicho que la mejor manera de interpretar erróneamente un currículum es basándonos en planes, programas de estudio y libros escolares, lo más importante a destacar es que éstos tienen un significado a la vez simbólico y práctico: expresan y legitiman ciertos objetivos deliberados de la escolarización y permiten conocer aquello que en cierta época se consideraba socialmente útil, no obstante que eso no nos garantice un detallado conocimiento sobre la forma y lo que efectivamente aprendieron los estudiantes. ${ }^{79}$ Desde la historia social del currículum, en este artículo sólo hemos querido subrayar el nacimiento de la escuela moderna y los orígenes de la formación cívica y moral en México.$$
\text { (1) }
$$

\footnotetext{
del conocimiento a impartirse en el aula y, sobre todo, la influencia del mundo cultural del alumnado y las formas específicas, individuales, de cada estudiante para apropiarse de los contenidos, cuyo universo social y cultural lo condicionan: la lectura, situada en el universo personal, es una práctica de riesgo para el lector, el grupo y las distintas formas de poder.

79 Goodson, "La construcción social del currículum", pp. 10-11, 29-30.
} 


\section{Siglas}

AAP Archivo del Ayuntamiento de Puebla. Expedientes sobre escuelas. Escuelas.

\section{Fuentes y bibliografía.}

Aguilar Rivera, José Antonio

"El veredicto del pueblo: el gobierno representativo y las elecciones en México, 1809-1846", en Las elecciones y el gobierno representativo en México, 1810-1910, México, Fondo de Cultura Económica, Consejo Nacional para la Cultura y las Artes, Instituto Federal Electoral, 2010, pp. 123-164.

Alarcón Meneses, Luis Alfonso

"Manuales y textos escolares como fuente para la historia de la educación y la cultura en el Caribe colombiano", en Hugues R. Sánchez Mejía y Leovedis Martínez Durán (ed.), Historia, identidades, cultura popular y música tradicional en el Caribe colombiano, Valledupar, Unicesar, 2004, pp. 175-200.

Alonso Rodríguez, Pedro

Catón español político christiano. Obra original para la enseñanza y buena educación de los niños, niñas y jóvenes, acomodada al carácter, costumbres, leyes y religión de la nación española, con advertencias político-morales a los padres y maestros, Madrid, Imprenta de Aznar, 1804.

Ampudia de Haro, Fernando

"Una aproximación al proceso civilizatorio español", Praxis sociológica, Toledo, Universidad de Castilla-La Mancha, núm. 9, pp. 91-122.

Anderson, Benedict

Comunidades imaginadas: reflexiones sobre el origen y la difusión del nacionalismo, México, Fondo de Cultura Económica, 2003.

Arredondo López, María Adelina

"La formación de los ciudadanos de la primera República Federal Mexicana a través de un texto escolar (1824-1834)", en Carmen Castañeda García, Luz Elena Galván Lafarga y Lucía Martínez Moctezuma (coord.), Lecturas y lectores en la historia de México, México, Centro de Investigaciones y Estudios Superiores en Antropología Social, El Colegio de Michoacán, Universidad Autónoma del Estado de Morelos, pp. 67-87.

Benso Calvo, M. Carmen

"La urbanidad y la educación cívica como disciplinas escolares. Relación e implicaciones", Sarmiento. Anuario galego de historia da educación, Santiago de Compostela, Universidad de Vigo, Universidad de Santiago de Compostela, Universidad de La Coruña, núm. 12, 2008, pp. 35-55. 
Carrillo Prieto, Ignacio

La ideología jurídica en la constitución del Estado mexicano, 18121824, México, Universidad Nacional Autónoma de México, 1986.

Catecismo político mexicano para uso de las escuelas, México, Imprenta del Águila, 1828.

Chartier, Anne-Marie y Jean Hébrard, "Alfabetismo y escolarización desde el punto de vista de un historiador cultural", en Thomas S. Popkewitz, Barry M. Franklin y Miguel A. Pereyra (comp.), Historia cultural y educación. Ensayos críticos sobre conocimiento y escolarización, trad. José M. Pomares y Montse Casademunt, Barcelona, Ediciones Pomares, pp. 269-293.

Choppin, Alain

"L'histoire des manuels scolaires: un bilan bibliométrique de la recherche française", Histoire de l'éducation, París, Service d'histoire de l'éducation, Institut National de Recherche Pédagogique, vol. 58, núm. 1, 1993, pp. 165-185.

Choppin, Alain

"Los manuales escolares de ayer a hoy. El ejemplo de Francia", Historia de la Educación. Revista interuniversitaria, Salamanca, Ediciones Universidad de Salamanca, núm. 19, 2000, pp. 13-37.

Choppin, Alain

"Pasado y presente de los manuales escolares", en Julio Ruiz Berrio (ed.), La cultura escolar de Europa. Tendencias históricas emergentes, Madrid, Biblioteca Nueva, 2000, pp. 107-165.

Choppin, Alain

"Prólogo", en Carmen Castañeda García, Luz Elena Galván Lafarga y Lucía Martínez Moctezuma (Coords). Lecturas y lectores en la historia de México, México, Centro de Investigaciones y Estudios Superiores en Antropología Social, Universidad Autónoma del Estado de Morelos, El Colegio de Michoacán, 2004, pp. 13-19.

Connaughton, Brian F.

Dimensiones de la identidad patriótica. Religión, política y regiones en México. Siglo XIX, México, Universidad Autónoma de México, Miguel Ángel Porrúa, 2001.

Costeloe, Michael P.

La República central en México, 1835-1846. "Hombres de bien" en la época de Santa Anna, trad. Eduardo L. Suárez, México, Fondo de Cultura Económica, 2000.

Cuesta Fernández, Raimundo

Sociogénesis de una disciplina escolar. La Historia, Barcelona, Pomares-Corredor, 1997. 
D. J. C.

Catecismo político arreglado a la Constitución de la Monarquía Española para ilustración del pueblo, instrucción de la juventud, y uso de las escuelas de primeras letras, Puebla, Imprenta de San Felpe Neri, 1820.

Delgado de Jesús y María, Santiago

Catecismo de urbanidad civil y cristiana para uso de las escuelas y seminarios del Reyno, con las leyes de discreción de palabras, y ceremonias en todos los casos que pueden ocurrir en el trato, Vich, Imprenta de Ignacio Valls, 1819.

Díaz y Tirado, Joseph Atanasio

Sermón panegírico-moral que el veinte y ocho de octubre del año de 1794 y último día del solemne novenario de desagravios, que con motivo de las actuales guerras contra los franceses dedicaron los parroquianos del Señor San Joseph a su santísimo protector y patriarca, en su iglesia parroquial. Predicó el Doctor Don..., Puebla, Impreso en la Oficina Palafoxiana, 1795.

Donzelot, Jacques

"Espacio cerrado, trabajo y moralización", en R. Castel et al., Espacios de poder, trad. Julia Varela y Fernando Álvarez-Uría, Madrid, Ediciones de La Piqueta, 1981, pp. 27-51.

Dussel, Inés

"Introducción", Revista de Estudios del Currículum, Barcelona, Pomares-Corredor, vol. 2, núm. 1, 1999, pp. 7-10.

Elias, Norbert

El proceso de la civilización. Investigaciones sociogenéticas y psicogenéticas, México, Fondo de Cultura Económica, 1994.

Escolano, Agustín

"La politique du livre scolaire dans l'Espagne contemporaine. Jalons pour une histoire", Histoire de l'Éducation, París, Service d'histoire de l'éducation, Institut National de Recherche Pédagogique, vol. 58, núm. 1, 1993 pp. 27-45.

Fleury, Claudio

Catecismo histórico del señor abad..., traducido al castellano y corregido de orden de la Real Junta Superior de Inspección de escuelas del Reino y mandado usar en todas ellas, Madrid, Imprenta Real, 1830.

Foucault, Michel

Vigilar y castigar. Nacimiento de la prisión, trad. Aurelio Garzón del Camino, México, Siglo XXI, 1988.

Foucault, Michel

Microfísica del poder, Julia Varela y Fernando Alvarez-Uría (ed. y trad.), Madrid, Ediciones de la Piqueta, 1979. 
Galván, Valentín

De vagos y maleantes. Michel Foucault en España, Barcelona, Virus editorial, 2010.

Galván, Valentín

La recepción académica de Michel Foucault en España: la pregunta por el saber (1967-1986)", en Revista de Hispanismo Filosófico, Madrid, Asociación de Hispanismo Filosófico, Fondo de Cultura Económica, núm. 14, 2009, pp. 101-127.

González Oropeza, Manuel

"Características iniciales del federalismo mexicano (1823-1837)", en Cecilia Noriega Elio (ed.), El nacionalismo en México. VIII Coloquio de Antropología e Historia Regionales, Zamora, El Colegio de Michoacán, 1992, pp. 413-432.

Guénot, Esteban

Plan de educación elemental y de varios establecimientos de utilidad pública y de beneficencia que somete a la aprobación de las cámaras de la República Mexicana, México, Imprenta del ciudadano Alejandro Valdés, 1826.

Guerra, François-Xavier

México: del Antiguo Régimen a la Revolución, trad. Sergio Fernández Bravo, México, Fondo de Cultura Económica, 1988, 2 vols.

Guerra, François-Xavier

Modernidad e independencias. Ensayos sobre las revoluciones hispánicas, México, Fondo de Cultura Económica, Editorial Mapfre, 1993.

Guzmán Batalla, Graciela

"Consideraciones en torno al desarrollo de la investigación histórica sobre los libros de texto en México, 1970-1995", en Gabriela Ossenbach y Miguel Somoza (coord.), Los manuales escolares como fuente para la historia de la educación en América Latina, Madrid, Universidad Nacional de Educación a Distancia, 2005, pp. 47-66.

Guzmán Hernández, Felipe (comp.)

Zacatlán. Escuela lancasteriana, Puebla, Secretaría de Cultura, 1995.

Hale, Charles A.

El liberalismo mexicano en la época de Mora (1821-1853), trad. Sergio Fernández Bravo y Francisco González Aramburu, México, Siglo XXI, 1999.

Hamilton, David

“Orígenes de los términos educativos 'clase' y 'currículum', Revista Iberoamericana de Educación, Madrid, Organización de Estados Iberoamericanos para la Educación, la Ciencia y la Cultura, núm. 1, 1993, pp. 201-222. 
Herrejón Peredo, Carlos

Del sermón al discurso cívico. México, 1760-1834, Zamora, El Colegio de Michoacán, El Colegio de México, 2003.

Hunter, Ian

Repensar la escuela. Subjetividad, burocracia y crítica, trad. José M. Pomares, Barcelona, Pomares-Corredor, 1998.

Johnsen, Egil Borre

Libros de texto en el caleidoscopio. Estudio crítico de la literatura y la investigación sobre los textos escolares, trad. José M. Pomares Barcelona, Pomares-Corredor, 1996.

Juliá, Dominique

"La cultura escolar como objeto histórico", en Margarita Mengus y Enrique González (coord.), Historia de las universidades modernas en Hispanoamérica. Métodos y fuentes, México, Universidad Nacional Autónoma de México, 1995, pp. 131-153.

Lanning, John Tate

El Real Protomedicato. La reglamentación de la profesión médica en el Imperio español, trad. José Luis Soberanes Fernández y Miriam de los Ángeles Díaz Córdoba, México, Universidad Nacional Autónoma de México, Facultad de Medicina, Instituto de Investigaciones Jurídicas, 1997.

Lardizábal y Uribe, Manuel de,

Discurso sobre las penas contrahido a las leyes criminales de España para facilitar su reforma, Madrid, Joaquín Ibarra impresor, 1782.

Lempérière, Annick

"De la nación corporativa a la nación moderna. México (1821-1860)", en Antonio Annino y François-Xavier Guerra, Inventando la nación. Iberoamérica, siglo XIX, México, Fondo de Cultura Económica, 2003, pp. 316-346.

Márquez Carrillo, Jesús

"¿Quién funda ciudades y reinos? Educación, suarecismo y filosofía política tomista en Puebla, 1680-1795", en Graffylia. Revista de la Facultad de Filosofía y Letras, Puebla, Facultad de Filosofía y LetrasBUAP, núm. 4, 2004, pp. 140-150.

Mateos Montero, Julio

"Problemas y apuntes para una historia crítica de la escolarización", Avances en supervisión educativa. Revista de la Asociación de Inspectores de Educación en España, Madrid, ADIDE, núm. 18, 2013. http:// www.adide.org/revista/index.php/ase/article/view/147/147.pdf

Mendarte Rocandio, Félis

Arte para la primera enseñanza de niños y niñas por el Sistema Mutuo, 
acompañado de 28 muestras y todas las teorías que necesita cada escuela, Veracruz, Imprenta de Félis Mendarte, 1828.

Mendiola, Alfonso

Retórica, comunicación y realidad. La construcción retórica de las batallas en las crónicas de la conquista, México, Universidad Iberoamericana, 2003.

Meneses Morales, Ernesto

Tendencias educativas oficiales en México, 1821-1911, México, Porrúa, 1983.

Meníndez Martínez, Rosalía

"La Historia de la Educación en México: nuevos enfoques y fuentes para la investigación", Sarmiento. Anuario galego de historia da educación, Santiago de Compostela, Universidad de Vigo, Universidad de Santiago de Compostela, Universidad de La Coruña, núm. 13, 2009, pp. 151-164.

Moral Jiménez, María de la Villa

"Poder disciplinario y educación. Aproximación foucaultiana desde la psicología social", Athenea digital. Revista de pensamiento e investigación social, núm. 13, 2008, pp. 71-94. http://psicologiasocial.uab.es/ athenea/index.php/atheneaDigital/article/view/413.

Morey, Miguel

"Introducción: la cuestión del método", en Michel Foucault, Tecnologías del yo y otros textos afines, trad. Mercedes Allendesalazar, Barcelona, Paidós, Instituto de Ciencias de la Educación, Universidad Autónoma de Barcelona, 1991, pp. 9-44.

Ossenbach Sauter, Gabriela

"La investigación sobre los manuales escolares en América Latina: la contribución del proyecto MANES", Historia de la Educación. Revista interuniversitaria, Salamanca, Universidad de Salamanca, núm. 19, 2000, pp. 195-203.

Pineau, Pablo

"Premisas básicas de la escolarización como construcción moderna que construyó a la modernidad", Revista de Estudios del Currículum, Barcelona, Pomares-Corredor, vol. 2, núm. 1, 1999, pp. 39-61.

Pineau, Pablo

"A modo de introducción. Estética escolar: manifiesto sobre la construcción de un concepto", en Escolarizar lo sensible. Estudios sobre estética escolar, 1870-1945, Buenos Aires, Teseo, 2014, pp. 21-38.

Pineau, Pablo

"¿Por qué triunfó la escuela? o la modernidad dijo: Esto es educación, y la escuela respondió: Yo me ocupo", en Pablo Pineau, Inés Dussel 
y Marcelo Caruso. La escuela como máquina de educar. Tres escritos sobre un proyecto de la modernidad, Buenos Aires, Paidós, 2001, pp. 306-331.

Plan de escuelas de primeras letras arreglado al nuevo sistema de Lancaster, llamado de la enseñanza mutua, Puebla, Oratorio de San Felipe Neri, 1819.

Popkewitz, Thomas S.

"Infancia, modernidad y escolarización: nacionalidad, ciudadanía, cosmopolitismo y 'los otros' en la constitución del sistema educativo norteamericano", Infancia y escolarización en la modernidad tardía, Madrid, Akal, Universidad Internacional de Andalucía, 2002, pp. 17-69.

Popkewitz, Thomas S.

"La producción de razón y poder: historia del currículum y tradiciones intelectuales", en Thomas S. Popkewitz, Barry M. Franklin y Miguel A. Pereyra (comp.), Historia cultural y educación. Ensayos críticos sobre conocimiento y escolarización, trad. José M. Pomares y Montse Casademunt, Barcelona, Pomares, 2003, pp. 146-184.

Popkewitz, Thomas S.

Sociología de las reformas educativas. El poder/saber en la enseñanza, la formación del profesorado y la investigación, trad. Pablo Manzano, Madrid, Fundación Paideia, Morata, 2000.

Quijada, Mónica

"¿Qué nación? Dinámicas y dicotomías de la nación en el imaginario hispanoamericano", en Antonio Annino y François-Xavier Guerra, Inventando la nación. Iberoamérica, siglo XIX, México, Fondo de Cultura Económica, 2003, pp. 287-315.

Reyes Morales, Cayetano

"Un día de clases en la época colonial", Relaciones. Estudios de Historia y Sociedad, Zamora, El Colegio de Michoacán, vol. v, núm. 20, 1984, pp. 7-35.

Ríos Zúñiga, Rosalina

"Making Citizens. Civil Society and Popular Movilization in Zacatecas, Mexico, 1821-1853", Pittsburgh, University of Pittsburg, 2002 (tesis de doctorado).

Roldán Vera, Eugenia

"Making Citizens: An Analysis of Political Catechisms in Nineteenth-

Century Mexico", Universidad de Warwick, 1996 (tesis de doctorado).

Sagredo Baeza, Rafael

"Actores políticos en los catecismos patriotas y republicanos americanos, 1810-1827", Historia Mexicana, México, El Colegio de México, vol. XLV, núm. 3, 1996, pp. 501-538. 
Serrano, Sol

"La escuela chilena y la definición de lo público", en François-Xavier Guerra et al., Los espacios públicos en Iberoamérica. Ambigüedades y problemas. Siglos XVIII y XIX, México, Centro de Estudios Mexicanos y Centroamericanos, Fondo de Cultura Económica, 1998, pp. 340-362.

Tanck de Estrada, Dorothy

La educación ilustrada, 1786-1836. Educación primaria en la ciudad de México, México, El Colegio de México, 1984.

Tanck de Estrada, Dorothy

"Los catecismos políticos: de la Revolución francesa al México independiente", en Solange Alberro et al., La Revolución francesa en México, México, El Colegio de México, 1992, pp. 65-80.

Tanck de Estrada, D.

"La alfabetización: medio para formar ciudadanos de una democracia, 1821-1840", Historia de la Alfabetización y de la Educación de Adultos en México, t. I, México, Secretaría de Educación Pública, Instituo Nacional para la Educación de los Adultos, 1994, pp. 109-131.

Taylor, William B.

“...de corazón pequeño y ánimo apocado. Conceptos de los curas párrocos sobre los indios de la Nueva España del siglo XVIII", Relaciones. Estudios de Historia y Sociedad. Zamora, El Colegio de Michoacán, 1989, vol. X, núm. 39, pp. 5-67.

Torres Septién, Valentina

"Notas sobre urbanidad y buenas maneras: de Erasmo al Manual de Carreño", en Pilar Gonzalbo (coord.), Historia y Nación. Historia de la educación y enseñanza de la historia, México, El Colegio de México, 1998, pp. 89-111

Varela, Julia

"Elementos para una genealogía de la escuela primaria en España", en Anne Querrien, Trabajos elementales sobre la escuela primaria, trad. Julia Varela, Madrid, Las Ediciones de la Piqueta, 1979, 169-198.

Varela, Julia

"Conocimiento, poder y subjetivación en las instituciones educativas. Sobre las potencialidades del método genealógico en el análisis de la educación formal e informal", en Thomas S. Popkewitz, Barry M. Franklin y Miguel A. Pereyra (comp.), Historia cultural y educación. Ensayos críticos sobre conocimiento y escolarización, trad. José M. Pomares y Montse Casademunt, Barcelona, Pomares, pp. 127-145.

Vargas, M. M.

Catecismo de República o elementos del Gobierno Republicano Federal de la Nación Mexicana, México, Imprenta a cargo de Martín Rivera, 1827. 


\section{Viñao Frago, Antonio}

"La escuela y la escolaridad como objetos históricos. Facetas y problemas de la historia de la educación", História da Educação, Pelotas, Associação Sul-Rio-Grandense de Pesquisadores em História da Educação, vol. 12, núm. 25, 2008, pp. 9-54.

Recibido: 18/02/2013. Aceptado: 25/11/2015 